\title{
Egalitarian Distributive Justice and Reasoning Luck
}

\author{
Alexey Chernyak \\ Faculty of Humanities and Social Sciences \\ Peoples' Friendship University of Russia \\ Miklukho-Maklay str., 10/2, Moscow, Russia, 117198 \\ E-mail: abishot2100@yandex.ru
}

\begin{abstract}
Luck Egalitarianism is an intensively developing theory of distributive justice, one of the most intriguing social problems of all times. This theory requires that only those distributive inequalities which result from peoples' wrong choices are allowed; and, in some versions, the account even recognizes such inequalities as being just. But wrong choice may also be a matter of personal bad luck of its agent; this posits a problem for a Luck Egalitarian: as matters of luck, the disadvantages caused by such wrong choices should be neutralized in spite of the fact that their agents could choose otherwise. In the following article, the nature of this problem will be analyzed, and some solutions will be observed.
\end{abstract}

Keywords—justice; ribution; luck; reasoning; egalitarianism; inequality; decision; difference

\section{INTRODUCTION: EGALITARIAN DISTRIBUTION AND LUCK}

Many people consider equality an important value. Some philosophers claim that it is a moral ideal. They are called egalitarians. Equal attitude to those who are supposed to be equal is one egalitarian value, whereas equal access to certain values, such as welfare, opportunities, rights, responsibilities, resources etc., is another. Egalitarian ideology regarding just distribution of values between individuals or parties roughly consists in the belief that equal distribution is morally good by itself. [1] Strict equality cannot be realized in practice: even if each member of a group of people gets all the same as any other they may value same things differently, and some may consume/exploit them faster or better than the other. Both of these effects create inequality from an initial equality.

In response to intrinsic inequalities of people in the real world, J. Rawls formulated his famous Difference Principle which allows economic inequality so far as it results from basic equalities of rights, burdens, and opportunities (access to professions and services) and serves the benefit of the most disadvantaged members of society. [2] $\mathrm{He}$ also observed that every person's starting point in society is the outcome of a natural lottery which determines the biological potential of a person, and a social lottery consisting in political, social, and economic circumstances into which the person is born; thus a person's welfare is a matter of good or bad luck [11. P. 74-75]. [3]

R. Dworkin agrees with Rawls that initial access to resources and opportunities for everyone must be equally distributed in order to neutralize the results of natural and social lotteries, both bad and good luck; he claims that the second part of the difference principle, which defines the just distribution of welfare, should apply only to those who became economically disadvantaged due to some sort of bad luck. According to him, those who became worse off because they made wrong choices do not deserve compensation by way of redistribution of what belongs to those who are better off due to their right choices and hard work [5. P. 74].

This account shares with Rawls' theory a number of problems, one of which is how to obtain equality of initial positions? Only some of initial inequalities may be in principle (although far not always in reality) eliminated or compensated by state or society, mostly social ones, but, for example, we can do nothing with natural inequalities determined by genetics.

However, Luck Egalitarianism, as this program was called, seems to be at least a good idea of egalitarian just distribution. [4] The general idea behind it is that those and only those who are worse off due to their bad luck, or more specifically, brute bad luck, should be compensated by way of more just redistribution of shares [4. P. 5, 29]. Differential standings affected by luck are morally undesirable and unjust [2. P. 85]. And "fortunate individuals should give up resources to improve the life prospects of those whose initial conditions" are the upshot of bad luck [ 3 . P. 227].

\section{BRUTE LUCK AND OPTION LUCK}

The notion of brute luck involved in this model requires clarification. Usually, brute luck is distinguished from option luck where the latter is a matter of "whether someone gains or loses through accepting an isolated risk he or she should have anticipated and might have declined" [5. P. 73]. Brute luck in turn is understood as constituted by outcomes of risks which agents could not anticipate and decline [5. P. 73].

The matter of definition of brute luck is complicated, though. Indeed, people would normally make a difference between the one who did the best she could to achieve some goal which was in principle achievable for her but failed due to the contingencies she could not control and the one who preferred to do nothing relevant to achieve the same goal if they had to decide what each deserves. Most likely a 
rational person interested in justice would decide that if anyone deserves compensation in such situation, the former deserves it more than the latter, considering what each of them did and is responsible for. Would the rational person change her mind given the knowledge that the first deliberately took some risk and failed because of this risk? This would depend on a number of further considerations. For example, a person might have a choice between more and less risky strategies such that the most risky one would give the greatest benefit; if she had chosen the most risky strategy because of its possible and greater valuable outcome, she might be judged fully responsible for this choice, hence deserving no compensation. But if the only choice she had was between the chosen risky strategy and yet more risky ones, she would rather be considered a victim of bad brute luck, if failed, in spite of the fact that she could anticipate and decline the risk she took.

Perhaps brute luck never intervenes into actions without any option luck, and vice a versa. [1] And bad brute luck may be not the only form of bad luck generating inequalities which an egalitarian could like to see properly compensated or neutralized. [2] However, I would not go deeper into these matters for the sake of briefness; anyway it can be claimed that whenever inequality is produced by bad brute luck (pure or not) it should be a reason for a more just redistribution.

It is also a matter of discussion whether an egalitarian compensation of inequalities grounded in brute luck should have a character of luck-neutralization. [1] Thus, it may be argued that if a state takes some part of a share of the one who is better off due to some good brute luck and gives it to someone who is worse off due to some bad brute luck may be interpreted as a kind of good brute luck for the later. To this it may be responded that "neutralization" here should not mean "elimination" of any dependence of just distribution on brute luck, but rather means that certain effects of luck call for redistributive compensation.

\section{THE INCOHERENCE PROBLEM}

Many Luck Egalitarians' insights raise questions, but some criticism seems to be especially powerful. Thus, many decisions which people make affect other people who are not themselves responsible for these decisions; an outcome of such decision may make someone who is not responsible for it (didn't choose to make it) worse off. As G. Cohen generalized it, "one man's choice is another man's luck" [4. P. 143]. One famous example is that of children whose parents' wrong decisions make them worse off. This is their sheer bad luck that their parents made such decisions.

Taking these cases into account, D. Miller claims that they make Luck Egalitarianism incoherent, as it stands. For on one hand, it allows and even legitimates inequalities caused by different personal choices, whereas on the other hand, it requires that all inequalities contributed by brute luck were neutralized (compensated) [9. P. 9-11]. Then if, for example, one person makes a gift to another one, all those who could also receive a gift from the same person and become worse off because they didn't should be compensated for not receiving the gift [9. P. 12]. Whoever may be required to compensate them (the one who makes a gift, those who did not make gifts or some social institution) the very idea of such compensations seems invalid.

It may be wondered whether the observed conflict of Luck Egalitarianism's interests really makes this theory incoherent; however, it produces a serious problem for it. But, according to Miller, Luck Egalitarianism is at least coherent when applied only to cases when ones' personal decisions do not affect others. Thus, he suggests to imagine the situation when individuals in some society are equally well off in the initial position, i.e. hold resources of different kinds which give them the same level of advantage. Then they make decisions which alter their level of advantage and create inequalities. Since their decisions are the only source of the inequalities, and all inequalities caused by brute luck were eliminated on the initial position, the resulting inequalities shouldn't be compensated [9. P. 7].

But wrong decisions, i.e. those which (if accomplished) make an agent worse off in comparison with his or her previous condition, may also result from bad brute luck of their agents; an agent may be just not reasonable or rational enough, have not enough intellectual power or access to information to make right decision in certain situation. In general, an agent making a decision about some issue $\mathrm{P}$ in certain situation $\mathrm{S}$ may both have wrong reasons, i.e. such that don't support right decision relative to $\mathrm{P}$ in $\mathrm{S}$, and be unable to have better reasons to decide about $\mathrm{P}$ in $\mathrm{S}$. Negative outcomes, economic disadvantages and inequality in particular, of wrong decisions which their agents couldn't help themselves not to make due to their personal inabilities to make right decisions in certain situations, may be still claimed to require compensation or correction even when no one but those agents themselves is affected by these decisions.

\section{TALENT AND EFFORT}

It is normal to consider people responsible for their decisions so far as 1) some alternative decisions are supposed to be available to them in the situations where the decisions were made, and 2) the choice of a decision among available alternatives reflects the level of effort which a person made in order to make the best decision she could in her current situation. Most luck egalitarians suggest that how much talent people have is a matter of luck, whereas how much effort they produced is not. According to them, people who have different levels of talent, but made the same effort, should end up equally well off under the condition of just luck-egalitarian distribution; meanwhile, people who have the same level of talent but made different efforts may not (or even shouldn't) end up equally well off. Then, the idea that wrong decisions may be a matter of bad brute luck seems to presuppose that personal decisions reflect rather personal level of talent than their level of effort. Nevertheless, it is quite clear that even if a person makes a wrong decision because of some lack of talent (inability to acquire enough logical competence, for instance), she may be said to have made insufficient efforts to improve her decision-making process. Thus, she might 
ask more competent people for help or to try and accommodate more information. The fact that she didn't do anything like that may be called a matter of her responsibility which makes her wrong decision due to lack of talent her fault anyway.

Of course, in some cases, the decision simply must be made here, now, and fast. There or seems to be no option to delay the decision-making in order to use some help or wait for better conditions. Thus, if a person makes a valid inference in situation $S$ and she wasn't under certain emotional or time pressure which, in fact, prevented her from doing her best reasoning in $\mathrm{S}$, she may be called having made wrong decision because she applied too little effort in S.Her actual low effort may reflect her bad circumstantial luck because she couldn't choose not to make a decision in question in circumstances beyond her control which prevented her from doing her best reasoning in S.1 Even if we accept that all full-fledged decisions, i.e. what persons may literally choose among alternatives, depend on personal efforts of their agents, there is still room for decisions which are matters of bad or good brute luck.

Wrong decisions may be made by different reasons. One of them is the intention to correct effects of some previously made wrong decision. The intention may be itself wrong2: e.g., trying to correct the effect of some lie an agent may decide to lie again in order to make an audience believe that she was right in the first case. But the intention may be right, and, nevertheless, an agent may be a hostage of what she did before, i.e. have no other option than to become yet more disadvantaged now in order to get some advantage later, and ideally, return to the position which she was in before the first decision in the series of wrongdoings had been accomplished. Thus, an agent may accept that she lied before and become immediately worse off by being publicly accused in order to be later pardoned and her authority reestablished. Although she is responsible for the previous decision, it is her bad, brute luck that she now has to make the wrong decision. Since the better in the short run decision might be chosen, an agent may be called responsible for making the wrong one in the current situation, but since in the long run the choice she has made was the best, it may be said to be an agent's bad brute luck that wrong decision was the best long run choice she had in her current situation.

Another usual cause of wrong decisions is negligence which presupposes that if an agent had enough resources (time, logic, information etc.), they could use them properly and had to do this in her current situation to make right decision but failed to make it anyway. Therefore, it is normally perceived as something which an agent could avoid if enough effort is made and, hence, is responsible for the matter. But negligence itself may be an outcome of an agent's bad brute luck if she couldn't not to be negligent, given what person she is by nature (due to genes and the way she was raised and educated). In general, the low level

\footnotetext{
${ }^{1}$ The description of this case as that of a contribution of person's bad brute luck to her wrong decision will look yet more relevant if a person had no better option than to make a decision in question in $\mathrm{S}$.

${ }^{2}$ By wrong intention I don't mean here morally bad one: only the one which leads (if realized) to some disadvantage.
}

of effort may itself be determined by a certain set of talents, being a matter of bad brute luck.

In many cases, the level of effort is itself a matter of luck. Thus, a gifted musician may have to spend most of her time earning money for life, hence, not having enough time to train her talent. It is then her bad luck of being poor which prevented her from making more efforts in order to develop her talent. The degree of a talent often depends on how much effort was made by an agent in order to develop it. As Rawls noted, it is often plausible that one's present level of talent reflects past effort, and one's level of effort is a matter of good or bad luck [11. P. 74].

Wrong reasoning 3 leading to wrong decision perhaps is something which an agent could in principle improve, but some counterfactual conditions under which she could do this presuppose too much change of what the agent or her world is. If in order to think better about $\mathrm{P}$ in a situation $\mathrm{S}$, make better relevant effort, an agent $X$ had to be mentally designed in a way significantly different from how she is actually designed, $\mathrm{X}$ 's inability to think better about $\mathrm{P}$ in $\mathrm{S}$ may hardly be considered her actual fault and responsibility. Although she may still be called responsible for making a decision about $\mathrm{P}$ which she made (since she could alternatively restrain from making any decision) she hardly seems to be literally responsible for being wrong as a result of this decision. [11]

\section{REASONING LUCK}

A complex ability to make right choices is normally partly a matter of natural and social lotteries: what intellectual capacities a person was born with and what patterns of decisions she internalized; these are not literally chosen by a person. Some people are unlucky in having no access to some information which would improve their decision-making. Other have to make some decisions in circumstances which require from them more talent or effort than they can produce. In any such case, if a person would make a better decision given better conditions for reasoning relative to a subject of decision and the situation (better access to information, better competence, better logic and other intellectual capabilities etc.), but could not choose what such conditions to be in relative to these subject and situation, her wrong decision may be called her bad reasoning luck.4

On the other hand, if a person had little chance to come to right decision even under the condition of doing her best (making enough intellectual effort), this would hardly excuse her not doing her best thinking in her current situation if she could do it; it wouldn't be her second-order

\footnotetext{
${ }^{3}$ Here "wrong" means "not in accord with certain formal scheme or set of rules", e.g. logic.

${ }^{4}$ How brute this luck is? It may be noted that at least rational agents have some partial control over their reasoning; they may be cautious not to make decisions if not enough relevant information is given, for example, and may even be demanded to be thus cautious as rational agents. But on the other hand the very inability to apply in certain circumstances an ability which an agent has, e.g. to be cautious enough, may result from some bad brute luck of having not enough talent for this; therefore at least in a sense reasoning bad luck seems to be brute.
} 
luck eliminating her responsibility for the wrong decision made by her.

The idea of reasoning luck is based on the counterfactual notion of responsibility proposed by G. A. Cohen. According to him, $\mathrm{Y}$ is a matter of luck for $\mathrm{X}$ if, and only if, (i) $\mathrm{X}$ is not responsible for $\mathrm{Y}$; and (ii) $\mathrm{X}$ is not responsible for $\mathrm{Y}$ if, and only if, $\mathrm{Y}$ is not the result of a choice made by $X$ and $X$ would not choose $Y$ if $X$ could [4. P. 33]. Suppose that $\mathrm{Y}$ is wrong decision. The relevant idea of reasoning luck then is that 1) $\mathrm{X}$ wouldn't chose to make $\mathrm{Y}$ if she made the decision in better thinking conditions (being better intellectually equipped, having better access to information or thinking in a situation where nothing which $\mathrm{X}$ didn't choose would prevent her from thinking as good as she could), 2) X's actual being in worse thinking conditions is not a result of X's free choice, and 3) although $X$ may be said having chosen $\mathrm{Y}$ among a number of alternatives she at the same time didn't freely choose not to make a decision better than Y since all alternative decisions she could choose in her current conditions were yet worse than Y. In this situation, $\mathrm{X}$ is not responsible for wrong decision $\mathrm{Y}, 5$ and her choosing $\mathrm{Y}$ is a matter of $\mathrm{X}$ 's bad reasoning luck. [13]

There is a well-known problem with the idea of luck based on the lack of control and responsibility. As Thomas Nagel writes: "Everything seems to result from the combined influence of factors, antecedent and posterior to action, that are not within the agent's control. Since he cannot be responsible for them, he cannot be responsible for their results" [10. P. 35]. So, if a Luck Egalitarian believes that if the causes of $Y$ are matter of luck for an agent $X$, so is $\mathrm{Y}$, she may end up with no responsibility for actions at all.

But consider two persons. The one, $\mathrm{Z}$, is in worse thinking conditions in a situation $S$ in comparison with the other, X; both Z's access to the relevant information and internal logic leave $\mathrm{Z}$ little chances to make right decision in $\mathrm{S}$, whereas chances which $\mathrm{X}$ has to make right decision in $\mathrm{S}$ are much higher due to X's intellectual capabilities, access to information etc.; $\mathrm{X}$ is better fitted to making decisions in $\mathrm{S}$ than $\mathrm{Z}$. In fact both make wrong decisions of the same kind in S. But $\mathrm{Z}$ made it because his being in bad thinking conditions in S. Since he chose neither his actual thinking conditions nor his being in $S$, he may be said to be not actually responsible for his wrong decision in $\mathrm{S}$. He would most probably make either the same or some other wrong decision in the similar situation if his thinking conditions weren't significantly improved. And if he couldn't choose to improve them he may be said to be also counterfactually non responsible for his wrong decision. Z's wrong decision wasn't an incident; it was rather what he would most likely produce in $\mathrm{S}$, given who he is. $6 \mathrm{X}$ also may be not actually responsible for her wrong decision in $S$ if she made a mistake in reasoning which she couldn't choose not to make, since it was an outcome of some antecedent events and circumstances which were not under X's control. The mistake is but an incident for $\mathrm{X}$ if causing an $\mathrm{X}$ 's wrong

\footnotetext{
${ }^{5}$ She is responsible for $Y$, but not for the fact that her decision is wrong.

${ }^{6}$ Moreover, he only could make right decision in $\mathrm{S}$ by chance, i.e. due to some circumstantial brute luck.
}

reason in $\mathrm{S}$ it doesn't affect her intellectual potential available in S. If $X$ didn't make such mistake she would most likely make right decision in S. But, although $X$ couldn't prevent making a mistake, she may be thought responsible for letting herself becoming a victim of this mistake; for she could avoid basing her decision on this mistake by making more efforts, be more careful, critical etc. Given how well her intellectual capabilities fit to making decisions in $S$ she could correctly expected to be able to neutralize possible negative effects of incident mistakes in $\mathrm{S}$. Since not being wrong in $\mathrm{S}$ is normal for $\mathrm{X}$, but not for $\mathrm{Z}$, given the differences in their thinking conditions in $S, X$, unlike Z, may be claimed responsible for a kind of negligence consisted in that $X$ accepted the result of the reasoning which didn't correspond to the pattern of X's doing her best in $\mathrm{S}$ as if it does correspond to this pattern. So, $X$ remains partly responsible for her wrong decision in $S$ even if she is not responsible for the mistake as such which made the decision wrong. $\mathrm{Z}$, in comparison, is not in the same sense responsible for his wrong decision.

Taking these considerations into account it may be claimed that a person may be comparatively responsible for her reasoning and its results in spite of the fact that no action is under a sufficient amount of a person's control.

It may be also objected that the very condition of equalized initial positions guarantees the elimination or neutralization of effects of reasoning luck. But so far as initial equality embraces only economic values, the amount of holdings, welfare etc., and access to social services (opportunities), the possibility that some people would still be worse off as rational agents in comparison with others, and be guided in their decision-making by wrong intentions, fallacies, superstitions, invalid logic etc. without literally choosing to be guided by these ordinary mental causes of wrong decisions, cannot be excluded. On the other hand, if we require that initial positions of agents of just distribution should be strictly equal, allowing no difference at all in individual intellectual capabilities and other talents contributing to reasoning, besides being too restrictive and nonrealistic this condition would look morally unacceptable. Its satisfaction presupposes something very close to an elimination of personal differences, enormous standardization of genetic and social forms of life etc.

\section{INSTITUTIONALIZED LUCK AND UNDESERVED FALLACIES}

Certainly it would be absurd to demand that any effect of bad reasoning luck should be compensated, and yet more absurd it would be to require that those who had benefited from good reasoning luck should pay for this. For if every intellectual disadvantage was compensated that would most likely motivate people to quit being rational and avoid wrong decisions. If you can benefit from being a victim of some disadvantage which does not in itself make you suffer (if only a little) why suffer side-effects of education, training and hard mental work (such as fatigue and loss of time) in order to become more rational if you end up with the same or almost the same share as those who are less rational, anyway? Being rational would risk becoming 
dominated strategy then. Does it follow from this that there is no way for Luck Egalitarians to make effects of bad brute reasoning luck neutralized without making those who happened to be more fortunate in this respect to pay for that, and hence lose their benefits of being rational?

Perhaps it may be at least demanded that some specific effects of bad reasoning luck be neutralized? Thus, one proposal is institutional luck egalitarianism, according to which natural facts about persons may make some of them luckier than the other, but it is crucial that institutions should not be designed so as to turn those facts about people into social advantages or disadvantages for them [13. P. 103-104]. We can agree that such phenomena as institutionalized racial segregation, for instance, are morally bad and should be excluded. But many forms of inequalities based on natural differences are generated by social institutions without being themselves institutionalized. Suppose that two people had the same amount of holdings in their initial position. While the one used her share wisely and therefore managed to preserve her level of economical advantage, another one being misguided by the false belief that he is lucky gambler invested all his money into a highly risky enterprise and lost them without any benefit. Indeed, it is due to the design of existent economical institutions that this person became disadvantageous because of his fallacy. If, for example, he acted in economic environment where everyone got whatever she needed whenever she needed it, he wouldn't become significantly economically worse off due to his wrongdoing. Also, it may be said that since the person in question is a product of certain education system this system's institutions are partly responsible for his being not rational enough to avoid fallacies like the described one. We can hardly find any social advantage or disadvantage which wouldn't be provided by some social institution in some way. So, in a sense, no inequality based on luck is strictly non institutional.

Then, it may be claimed that luck egalitarian just distribution should only prohibit institutionalization of advantages or disadvantages generated by natural differences or conversion them into moral norms. But in this case, too many brute-luck-based inequalities would remain outside luck-egalitarian concern; and this would look rather like giving up the main idea of Luck Egalitarianism than its realization.

Thus, wrong decisions are often based on fallacies of different sorts. What fallacy is, and what kind of beliefs are opposite to it, is a matter of discussion. But, here by fallacy I understand simply a belief which contradicts to the complete set or the majority of relevant evidence where a set of such evidence is somehow fixed by a convention of experts or a dominating tradition and in general accepted by an agent of fallacy. Thus, a belief of a person $\mathrm{X}$ that he is lucky gambler may be a fallacy without being objectively false: it would suffice that the majority of propositions conventionally suggested as the evidence about the world of $\mathrm{X}$ and which $\mathrm{X}$ would recognize as such evidence contradicted to that belief. It is possible that all these propositions are false, and the belief in question is true; it is possible that in 99 cases from $100 \mathrm{X}$ would benefit a lot from the investment which he did, and that the fact that he lost was due not to his being unlucky as a gambler but to some very unlucky coincidence of circumstances which prevented him from realization of his potential of lucky gambler in this particular situation. The belief would nevertheless be an apparent X's fallacy if only X wouldn't be justified in preserving it relative to the majority of relevant evidences about his world which he had or had access to. It means that it was sufficient for $\mathrm{X}$ to do some simple critical job of tracking down the consistency of the belief in order to find good reasons to reject it or at least not to use it in making important decisions. Now, if $\mathrm{X}$ could do this job and get rid of the fallacy before making a decision based on it, he may be considered responsible for not doing this and deserving the disadvantage which was caused by the decision in question. But if X couldn't get rid of the fallacy when it was crucial for avoiding making wrong decision, it may be his bad luck. This bad luck may be simply circumstantial if X's failure to see the incoherence of his belief was caused by some temporal delusion which prevented him from doing what he could otherwise do in the particular situation. In this case, if $X$ tried to justify the belief in the same situation some other time, he would most likely succeed and come to right conclusion. He was unlucky to try it in this particular situation then. But also this may be partly his bad reasoning luck: specifically, if X's mind was so designed as a result of his genetics and upbringing that in the situation where the belief had to be justified, he simply was unable to get proper access to the relevant evidence or to notice the contradiction between this evidence and the belief, or yet to make an inference that the belief is fallacious. $7 \mathrm{X}$ also could have no specific critical attitudes needed for setting the task of the belief's justification, again as a result of events in his past which he didn't chose to happen with him.

The fallacy which was not rejected simply because it was justified in wrong situation which circumstances prevented an agent from coming to right conclusion and which would be successfully rejected in most similar situations, may be called non-genuine or unstable. On the other hand, fallacies which their agents cannot reject because they are not sufficiently well intellectually equipped for this, given the set of situations where they may try to check the reasons for these beliefs and their other epistemic features, may be called genuine or stable. An agent may be rational enough to understand that she would be better off without fallacies, but be nevertheless not ready by some reason, which she could change, to make enough effort to improve her beliefs. She may be then said to be not critical enough. Hence, she is partly responsible for even stable fallacies she has. But someone may be glad to get rid of any fallacy and do what is needed for this but nevertheless unable to accomplish this task in respect of some fallacy F. We can imagine a world where such inability is provided by a series of temporal delusions casted by some powerful

\footnotetext{
${ }^{7}$ Another part of this luck is circumstantial, since in some other situation $\mathrm{X}$ could come to right conclusion about his belief under scrutiny but the current situation of justification was such that person's mental design didn't fit it which resulted in his failure to evaluate the belief properly.
} 
supernatural being, but a more plausible hypothesis is that having $\mathrm{F}$ was a matter of person's bad reasoning luck. It is due to how her mind was designed that she was unable to get herself rid of F. In this case an agent seems to be fully irresponsible for having F. Such stable fallacies may be called undeserved; their agents normally did nothing specifically in order to be victimized by them.

Now, it seems to be just from the point of view of Luck Egalitarian to see the difference in what those who became disadvantageous because of some undeserved fallacy deserves in comparison with those whose similar disadvantages were provided by their not undeserved fallacies. It is not enough to prohibit an institutional exploiting of undeserved fallacies; in many cases it is too clear that a wrongdoing based on such fallacy should be corrected or its outcomes compensated. The most sticking set of examples is provided by child behavior. Children normally have many inconsistencies in their beliefs since they are yet not trained enough critical thinkers; this makes them victims of fallacious decision-making. Often, such decisions may be qualified as bad reasoning luck of their agents. But adults often compensate negative outcomes of these decisions and give children second chances to do right things even in cases where a fallacy wasn't strictly undeserved. It may be said that this treatment is a reaction on the fact that the childish nature of agents of such wrongdoings and would be applied independently on whether the fallacy was deserved or not. But this is only partly true; adults are normally sensitive to the nature of child's wrongdoing. When they see that the wrong thing was done in spite of the fact that the kid who did it could avoid doing it and knew that it was a bad thing to do, they become more disposed to punish the kid for this wrongdoing rather than compensate its negative effects. The compensative attitude normally weakens when the fallacy which is responsible for a series of wrongdoings is recognized as what the kid could get rid of if she wanted or made more efforts. [15]

\section{CONCLUSION: MAKING JUSTICE TO IMPOSED FALLACIES}

Some fallacies stem not from agent's personal mistakes and blind contingencies but rather from the results of intentional indoctrination by someone else. By indoctrination, I here mean any manipulation with person's mind which results in violation of her free choice of what to believe: in this sense a belief in proposition $p$ is indoctrinated if an agent wouldn't come to believe in $\mathrm{p}$ given the same information about $\mathrm{p}$ if she reasoned by herself. What are the limits of this sort of indoctrination is a matter of discussion; certainly not every manipulation with mind has this effect. Thus, it may be said that logical argumentation is not a form of thus understood indoctrination since a rational agent is only provided in it with some information which she didn't have, and a logical reason to accept the thesis on the basis of this information. Since logic itself is already valued by an agent independently on that particular interaction, it may be said that she would accept the thesis without this particular piece of argumentation if the same information was somehow given to her. This case is quite different from the one when someone is, e.g., so charmed by a person who proposes the argument that becomes ready to believe that the argument is good in spite of its bad logic. In the later case, an agent may be said to suffer a delusion which she would be glad to get rid of if only she wasn't charmed, and the charm is outside her control. But in many other cases such as advertisement, something is shown to have value for an agent by demonstrating that it bears some feature which is already valued by her. This doesn't yet mean that the agent would come to believe what is proposed because she values the demonstrated feature without this particular interaction with her mind. In the same sense, an argumentation may be so constructed that its audience which wouldn't accept the thesis otherwise is accepting it because they like this particular argumentation.

Whatever, the indoctrination may be as to the good so to the bad; indoctrinated fallacies normally belong to the later set. If an indoctrinated fallacy is such that an agent would agree that she would be better off without it, it is not only undeserved but also imposed. In respect of such fallacies, it may be said that not only their agents are not responsible for having them, but there are some other persons or groups which are responsible for them. At least in such cases we seem to have those whom might be directly addressed the duty of compensating negative effects of undeserved imposed fallacies they are responsible for. These may be not available at the moment of an occurrence of the consequences in question, though, and in such cases it would be difficult to decide who should compensate the inflicted harm. But at least it seems fair enough that disadvantages caused by wrong choices and decisions which wouldn't be made if their agents weren't victims of undeserved imposed fallacies need to be compensated or otherwise neutralized in the name of Luck Egalitarian justice.

\section{REFERENCES}

[1] E. Anderson, "What is the Point of Equality?", Ethics, 109, 1999, 287-337.

[2] R. J. Arneson, "Equality and Equal Opportunity for Welfare", Philosophical Studies, 56, 1989, 77-93.

[3] R. J. Arneson, "Egalitarianism and Responsibility", Journal of Ethics, 3, 1999, 225-247.

[4] G. A. Cohen, On the Currency of Egalitarian Justice and Other Essays in Political Philosophy, Princeton, NJ: Princeton University Press 2011.

[5] R. Dworkin, Sovereign Virtue, Cambridge MA: Harvard University Press, 2000.

[6] R. Dworkin, "Equality, Luck and Hierarchy", Philosophy \& Public Affairs 31, 2003, 190-98.

[7] S.Hurley, Justice, Luck and Knowledge, Oxford: Oxford University Press, 2003.

[8] K. Lippert-Rasmussen, "Justice and Bad Luck", Stanford Encyclopedia of Philosophy, 2014.

[9] D. Miller, "The Incoherence of Luck Egalitarianism", Nuffield College, Oxford, 2014.

[10] T. Nagel, "Moral Luck", Mortal Questions, Cambridge: Cambridge University Press, 1979, 24-38. 
[11] J.Rawls, A Theory of Justice, Harvard, MA: Harvard University Press, 1971.

[12] J.Rawls, Political Liberalism, New York: Columbia University Press, 1993.

[13] K.C.Tan, Justice, Institutions, and Luck, Oxford: Oxford University Press, 2012. 